\title{
Risk of Revictimization of Intimate Partner Violence: The Role of Attachment, Anger and Violent Behavior of the Victim
}

\author{
Karlijn F. Kuijpers • Leontien M. van der Knaap • \\ Frans Willem Winkel
}

Published online: 14 September 2011

(C) The Author(s) 2011. This article is published with open access at Springerlink.com

\begin{abstract}
Victims of intimate partner violence (IPV) are known to be at high risk for revictimization. Yet, to date, the mechanisms explaining the link between victimization and revictimization of IPV have not been extensively studied. In the present prospective study involving 74 female helpseeking victims of IPV, we investigated victim-related psychological mechanisms that may underlie this link. With this study, we aim to contribute to the development of theory addressing these psychological mechanisms and their role in explaining risk for IPV revictimization. Hypotheses regarding possibly relevant psychological mechanisms were derived from two conflicting approaches to IPV: the gender perspective, and the mutual IPV perspective. Results lend further support to the mutual IPV perspective, since our final prediction model indicates that victim-perpetrated IPV is an important risk factor for physical and psychological IPV revictimization. An avoi-
\end{abstract}

At the time this study was conducted, the first author (Karlijn F. Kuijpers) was employed at the International Victimology Institute Tilburg (Intervict) at Tilburg University, The Netherlands. Currently she is working at the Institute for Criminal Law and Criminology at Leiden University, The Netherlands.

\section{K. F. Kuijpers $(\square)$}

Leiden Law School, Institute for Criminal Law and Criminology, Leiden University,

Room C 1.19, P.O. Box 9520, 2300 RA Leiden, The Netherlands e-mail: k.f.kuijpers@law.leidenuniv.nl

L. M. van der Knaap

International Victimology Institute Tilburg (INTERVICT),

Tilburg University,

Room M730, P.O.Box 90153, 5000 LE Tilburg, The Netherlands

F. W. Winkel

International Victimology Institute Tilburg (INTERVICT),

Tilburg University,

Room M735, P.O.Box 90153, 5000 LE Tilburg, The Netherlands dant attachment style shows to be a strong predictor as well, in particular for victims with high and average anger levels. Findings provide clear indications for risk assessment and treatment of IPV victims, and moreover offer opportunities to empower these victims in order to prevent future violence.

Keywords Attachment · Anger - Revictimization · Intimate partner violence $\cdot$ Risk assessment

Repeat victimization is an important issue that has received increasing attention within victimology over the last decades. Repeat victimization or revictimization refers to the observation that "one criminal victimization can be quickly followed by another, at a much higher rate than chance factors can explain" (Skogan 1999, p. 44). High rates of repeat victimization are reported for various crimes, for instance commercial burglary (40\%; Tilley 1993), schoolyard bullying (60-70\%; Pitts and Smith 1995) and sexual abuse (66\%; Classen et al. 2005). Similarly, the British Crime Survey reported high rates of revictimization for domestic violence; more than two-thirds of female victims of non-sexual domestic violence were revictimized within a year (Walby and Allen 2004). Vulnerability to crime thus appears to be distributed unevenly; a small group in the population experiences a large proportion of all crime (Farrell 1992). However, the development of a thorough theory describing the underlying mechanisms and links between risk factors and repeat victimization still lags behind.

Victimological theory has traditionally focused on victim-related lifestyle factors, including proximity to the perpetrator, risk-taking behavior, and other opportunity factors, such as being away from home, to explain revictimization (e.g., Miethe et al. 1987; Mustaine and 
Tewksbury 1998; Sampson and Lauritsen 1990). These factors are particularly useful with regard to crimes like burglary, but they appear insufficient in explaining revictimization of IPV for a number of reasons. First, offender proximity is a characteristic of IPV; all victims are or have been involved in an intimate relationship with the perpetrator. Offender proximity therefore can hardly be a defining characteristic of victims of IPV who are at risk for revictimization. Second, in lifestyle theories, risk for revictimization is explained by the fact that certain people engage in risk-taking behavior and expose themselves to more risky situations the moment before revictimization. IPV victims are all in a permanent high-risk situation and so this "risk exposure" will not be a distinguishing risk factor to explain IPV revictimization. Therefore, it appears that more or other factors are relevant in explaining IPV revictimization than victim-related lifestyle factors alone. Psychological mechanisms in victims that might underlie the link between IPV victimization and revictimization have been largely ignored until now (Bennett Cattaneo and Goodman 2005). By prospectively studying the role of such victim-related psychological mechanisms in explaining risk for IPV revictimization, the current study aims to make a contribution to the further development of theory.

An influential approach to explain repeat IPV was offered by Walker in her description of a cycle of violence (Walker 1984, 2000, 2009). In this cycle, a phase of tension building precedes the acute battering incident which is followed by a period of loving-contrition or absence of tension. A certain proportion of victims experiences this cycle over and over again, and according to Walker (1979), "repeated batterings, like electrical shocks, diminish the woman's motivation to respond" (p. 50). Walker's theory is explicitly based on the gender perspective on IPV. According to this perspective, IPV is characterized by one-sided violence, initiated by the male partner with the objective to dominate and control his wife (see for example Dobash and Dobash 1979; Walker 1984). In other words, IPV is used by men to achieve a specific goal (i.e., domination and control), and, therefore, it is also labeled instrumental violence. The victim is typically described as an anxious woman who largely depends on her violent partner, is afraid to be abandoned and believes things will get better.

A rather different perspective on IPV holds that both men and women perpetrate partner violence approximately to an equal extent (see Archer 2000), and that IPV can be initiated by men, but also by women (see Stets and Straus 1990). According to this perspective, IPV can mainly be described as an emotional response in reaction to an unpleasant experience and cycles of revictimization are thought to be characterized by mutual emotional aggression (see for example Dutton 2008a; Stets and Straus 1989). Within this perspective, male violence in the domestic context is seen as an emotional reaction to the frustration of the man's intimacy needs, such as perceived relationship dissolution or perceived abandonment (Daly and Wilson 1988; Dutton 2008b; Dutton and Browning 1988). Frustration of intimacy needs in men could be created by, for example, rejective and avoidant behavior of the female partner. Avoidant behavior, as part of an avoidant attachment style, can be described as feeling uncomfortable being close to others and having difficulties to trust and depend on others (Hazan and Shaver 1987).

Other victim behavior that, within the mutual IPV perspective, is thought to play a role in preserving a cycle of revictimization is the victim's own perpetration of violence against the partner (e.g., Stith et al. 2004). Dutton (1995) described a propensity for abusiveness in IPV perpetrators to indicate risk for recidivism. Such a propensity for abusiveness in victims might be hypothesized to pose a risk for revictimization of IPV. As Dutton reported several aspects of affective lability, such as insecure attachment, anger, and other behavioral expressions (e.g., borderline traits), to be related to reoccurrence of IPV in the perpetrator, similar aspects in victims might be related to revictimization of IPV. In fact, several aspects of affective lability, like insecure attachment styles (Bond and Bond 2004; Doumas et al. 2008; Henderson et al. 2005; Wekerle and Wolfe 1998), anger or aggression (Burman et al. 1993; Cordova et al. 1993; Ehrensaft et al. 2004; Jacobson et al. 1994; Moffitt et al. 2001), and the victim's own violent behavior against the partner (Anderson 2002; Capaldi et al. 2003; Fergusson et al. 2005; Stith et al. 2004) have been reported to be related to (re)victimization of IPV. However, these relations were mainly found crosssectionally and factors were examined separately, not concurrently.

The aim of the current study is to prospectively identify psychological mechanisms in victims that underlie the link between IPV victimization and revictimization. Relating the two conflicting IPV perspectives described above to psychological mechanisms, we expect different psychological mechanisms to support each perspective. Based on the gender perspective we would expect to find anxious attachment in victims to predict revictimization. The mutual violence perspective, however, would lead to a hypothesized relation between avoidant attachment in victims and revictimization. Both the gender as well as the mutual IPV perspective have received empirical support in crosssectional studies. For instance, some studies already showed an anxious attachment pattern in the victim to be related to IPV victimization (Bond and Bond 2004; Doumas et al. 2008), and others reported an avoidant attachment style in the victim to emerge repeatedly as a significant predictor for IPV victimization (Wekerle and Wolfe 1998). However, prospective studies in this field are 
scarce. The purpose of the current study is therefore to examine to what extent the two conflicting approaches to IPV are supported by prospective data by testing underlying psychological mechanisms. The gender perspective is represented in our hypothesis that an anxious attachment style of the victim will prospectively predict IPV revictimization. For the mutual IPV perspective, we hypothesize that an avoidant attachment pattern in the victim (leading to frustration in the male partner) prospectively predicts IPV revictimization. Furthermore, according to Winkel (1999) "frustration $[\ldots]$ in combination with some aggression cue is considered sufficient to elicit aggressive responses" (p. 275). Aspects of affective lability, such as victim anger and victim-perpetrated partner violence (see Dutton 1995), can typically be perceived as aggression cues. In line with this, we expect the risk for avoidantly attached victims to be particularly high when their partner additionally perceives some of these aggression cues. Therefore, we also hypothesize interactions between avoidant attachment and anger, and avoidant attachment and victim-perpetrated IPV when predicting risk for IPV revictimization.

\section{Method}

\section{Procedure and Participants}

Participants were from a large-scale, longitudinal study into revictimization among victims of IPV, and were recruited from various victim support services in the Netherlands in four large and four medium-sized cities. The services included a victim support office, a mental health organization, a number of social work organizations, a shelter, victim service points, and various local domestic violence teams. Participants were approached and included in our study if 1) they had been a victim of IPV at least once in the past 2 years, and 2) if they sufficiently mastered the Dutch language to understand the Dutch questionnaires we used. Participants were considered to be a victim of IPV if they had been abused physically, sexually or psychologically by their current or ex-partner. Victims were recruited through the collaborating victim support organizations by having staff inform eligible clients about this study. Most victims were directly contacted by staff members; others were informed about the study through a letter. Victims were told that we were conducting a study on risk for revictimization of IPV and were asked whether they were willing to participate. They were informed that, if they decided to participate, they had to fill in a questionnaire on the violence they experienced and possible complaints they might have developed. They were furthermore instructed that the questionnaire would be administered at three different moments in time: at entering the study, then
2 months later and a last time 6 months after the initial assessment. Participants were paid a 100 euro compensation for their time after completing the questionnaire at all three waves of data collection. Clients who indicated interest in participating received a registration form asking them to provide some personal data (name, address, phone number, and e-mail address) and to return it to the researchers. A researcher then telephoned registered participants to discuss any questions about the study they might have and to establish whether they preferred to fill in an online or a paper version of the questionnaire. It was also possible to plan a personal appointment with the researcher to complete the questionnaire. For any questions during completion of the questionnaire, participants could phone or e-mail the researchers.

Data that are reported in this paper were collected between August 2008 and March 2010. As mentioned above, this study is part of a three-wave, prospective study aimed at identifying victims at (high) risk of revictimization of partner violence. In this article, we present data from the first and second wave of data collection. In total, 162 victims participated in our study. However, as we decided to include the attachment measure in our questionnaire after we started recruiting respondents, our complete data set is limited to 74 participants. Although we aimed to study both male and female victims of IPV, all participants of our final sample of 74 victims were female.

\section{Measures}

\section{Time 1}

Attachment Attachment style of the victim was measured with the short form of the Experiences in Close Relationships Scale (ECR-S; Wei et al. 2007), consisting of 12 items. By the ECR-S, two forms of insecure attachment are measured; avoidant and anxious attachment (six items each). Wei et al. (2007) report the ECR-S to possess "a stable factor structure and acceptable internal consistency, test-retest reliability, and construct validity" (p. 201). A sample item of avoidant attachment is: "I am nervous when partners get too close to me"; and for anxious attachment: "I worry that romantic partners won't care about me as much as I care about them". Respondents were asked to indicate how they in general experience romantic relationships; not only referring to their most recent but also to prior romantic relationships. Items of the ECR-S are rated on a 7-point Likert scale ranging from 1 (disagree strongly) to 7 (agree strongly). Sum scores were computed for the anxious and avoidant attachment scale. The attachment styles measured by the ECR-S were thus treated as continuous, independent variables. Scale reliability in this 
study was fair as Cronbach's alpha for the avoidant attachment subscale was .65, and for the anxious attachment subscale .69. In general, a Cronbach's alpha of .60 or higher is considered a minimum acceptable level in case of short instruments used for screening purposes (e.g., Murphy and Davidshofer 1998, p.142-143), although some methodologists apply a stronger standard of at least .70 (Nunnally 1978).

Anger Anger in the victim was assessed with the Dimensions of Anger Reactions scale (DAR; Forbes et al. 2004; Novaco 1975). Apart from being a measure of trait anger, the DAR also reflects STAXI constructs (State Trait Anger Expression Inventory; Spielberger 1988) of anger out, state anger, and anger control. Therefore, the DAR is best described as a measure of anger disposition directed towards others (Forbes et al. 2004). It consists of seven items which are rated on a 5-point Likert scale ranging from 1 (not at all) to 5 (exactly so). The five response categories were adapted from the DAR5 (Hawthorne et al. 2006), as Hawthorne et al. (2006) report that "the nine response categories of the DAR were problematically labeled, [...] and prevented equivalent measurement when translated" (p. 166). A sum score was computed by adding up the responses on the seven items, thereby treating anger in the victim as a continuous independent variable. Sample items of the DAR are: "I often find myself getting angry at people or situations" and "When I get angry I stay angry". The DAR has been reported to be a reliable and psychometrically strong measure (Forbes et al. 2004). Scale reliability for the current study was good as well, as Cronbach's alpha was .85.

\section{Time 2 (Two Months Later)}

Severity of Physical and Psychological IPV Revictimization The two outcome measures of our study - severity of physical and psychological IPV revictimization - were assessed at follow-up after 2 months. We chose to measure these two specific outcomes because we know from literature that physical and psychological violence are the most common forms of IPV. Actually, according to studies by Dutton and Starzomski (1993) and Straus et al. (1980), psychological violence is even more common than physical violence. However, according to various studies (Follingstad et al. 1990; Walker 1984) psychological violence often occurs together with physical violence. Therefore, we were interested in what factors might predict these two common forms of IPV. Both severity of physical as well as severity of psychological IPV revictimization were measured with the revised version of the Conflict Tactics Scale (CTS2; Straus et al. 1996), a self-report measure of tactics used during relationship conflicts of dating, cohabiting or married couples. The CTS2 consists of 78 items listing conflict tactics or, in other words, violent behaviors for which respondents report the frequency of occurrence by either spouse. Thus, the CTS2 measures both violent behaviors that have been committed by a partner or expartner against the respondent (victimization measure), as well as the violent behaviors that have been perpetrated by the respondent him- or herself (perpetration measure). In this study we used the scores on the victimization measure of the CTS2 as our outcome variable. We assessed the occurrence of victimization by violent behaviors perpetrated by a partner or ex-partner during the past 2 months (i.e. IPV revictimization during the 2 month follow-up period). The items of the CTS2 are divided into five subscales: physical assault, psychological aggression, negotiation, injury, and sexual coercion. To assess severity of physical IPV revictimization we used the 12-item CTS2 subscale physical assault; for severity of psychological IPV revictimization we used the 8-item CTS2 subscale psychological aggression. For the CTS2 a good internal consistency has been demonstrated for all subscales, as well as adequate construct and discriminant validity (Straus et al. 1996). Sample items of the victimization measure of the CTS2 include "My (ex-) partner beat me up" and "My (ex-)partner kicked me" for the physical assault subscale, and "My (ex-)partner insulted or swore at me" and "My (ex-)partner called me fat or ugly" for the psychological aggression subscale. The CTS2 is usually scored using an 8-point ordinal scale indicating the frequency of occurrence of conflict tactics ranging from 1 (once in the past year) to 6 (more than 20 times in the past year), with 7 and 0 indicating "not in the past year, but it happened before" and "this has never happened" respectively (Straus et al. 1996).

According to Straus (2006), the CTS2 can be used as a frequency measure of conflict tactics, but also as a prevalence measure of violent behaviors, by instructing respondents to indicate if the behaviors had occurred or not, instead of how frequent. Accordingly, participants in the current study were asked to indicate the occurrence of victimization by each of the violent behaviors in the past 2 months by giving a "yes" or "no" answer, thus using the CTS2 as a prevalence measure. Sum scores for the revictimization measures of both physical and psychological IPV were computed by adding up the affirmative responses to the violent behaviors stated in the physical assault scale and psychological aggression scale of the CTS2. In doing so, we created two scales: 1) a scale for the variety of different physically assaultive behaviors, and 2) a scale for the variety of different psychologically assaultive behaviors by which one had been victimized. Participants with a higher sum score were victimized by a greater 
variability of physically or psychologically violent behaviors than participants with a lower sum score. Variety scales for violent behaviors have been used before by Moffitt et al. (2001) in their "Dunedin study". ${ }^{1}$ According to Moffitt et al. (1997), violence severity is often measured by frequency scores; however, variety scores have proved to be a good alternative. In this study we therefore interpret our variety score of violent behaviors as a severity measure of IPV. Variety scales are desirable because they are more reliable than frequency scores, particularly in the case of IPV (Moffitt et al. 2001). “"Has X happened?" is a more accurate response format than is "How many times has $\mathrm{X}$ happened?" especially among respondents whose violent acts have lost their salience because they happen frequently" (p. 15). In addition, variety scores are less skewed than frequency scores, and give equal weight to all violent acts (Moffitt et al. 2001). Cronbach's alpha for the CTS2 revictimization measure of physical IPV in this study was .93, indicating a high reliability (Murphy and Davidshofer 1998; Nunnally 1978). To obtain a satisfying reliability for our measure of psychological IPV revictimization, we first had to delete one item on the scale ("My (ex)-partner threatened to hit or throw something at me"), due to a high number of missing values on that item. Therefore, our final scale for psychological IPV revictimization consisted of seven items, for which a good reliability can be reported $($ Cronbach's alpha $=.83)$.

Severity of Victim-Perpetrated IPV Severity of IPV perpetrated by the victim herself was also assessed at follow-up after 2 months. Because violence used by the victim is often a direct reaction to the violence they receive from their partner (for example in self-defense or to express negative emotions evoked by the victimization), we decided to assess victim-perpetrated violence at the same time as our revictimization outcomes. In the current study, we focused on victim-perpetrated psychological IPV because this type of violence is more common than victimperpetrated physical IPV. ${ }^{2}$ Severity of psychological IPV perpetration by the victim was measured with the CTS2 (Straus et al. 1996). As explained previously, we used the CTS2 to measure severity of revictimization by looking at the victimization measure; however, to measure the victim's own perpetration of IPV we considered the perpetration measure of the CTS2. As mentioned in the above, the CTS2

\footnotetext{
${ }^{1}$ The Dunedin study is a longitudinal cohort study of more than 1,000 people born over the course of a year in Dunedin, New-Zealand. It started in 1972 and is still running. This multidisciplinary study provides information about various aspects of human health and development, including intimate partner violence.

${ }^{2}$ Only $8.1 \%$ of victims in our sample reported that they perpetrated some form of physical IPV, whereas almost half of the victims $(47.3 \%)$ reported to have perpetrated some form of psychological IPV.
}

is a self-report measure of tactics used during relationship conflicts of dating, cohabiting or married couples and consists of 78 items (39 for the victimization measure and 39 for the perpetration measure). A good internal consistency has been demonstrated for all subscales of the CTS2, as well as adequate construct and discriminant validity (Straus et al. 1996). We assessed the victim's own perpetration of psychologically violent behaviors against her partner or ex-partner during the past 2 months (i.e. the follow-up period) using the 8-item CTS2 subscale psychological aggression. Sample items include "I insulted or swore at my (ex-)partner" and "I called my (ex-)partner fat or ugly". Participants in the current study were asked to indicate their own perpetration of each of the violent behaviors in the past 2 months by giving a "yes" or "no" answer. Sum scores were computed by adding up the affirmative responses to the violent behaviors stated in the psychological aggression scale of the CTS2. In doing so, we created a scale for the variety of different psychologically assaultive behaviors which the victim had perpetrated herself. To obtain a satisfying reliability for our measure of victim-perpetrated psychological IPV, we again had to delete one item on the scale ("I threatened to hit or throw something at my (ex-)partner"), due to a high number of missing values on that item. Therefore, our final scale of victim-perpetrated psychological IPV consisted of seven items, for which an acceptable reliability can be reported $($ Cronbach's alpha $=.73)$.

\section{Results}

\section{Descriptives}

Our sample consisted of 74 female help-seeking victims of IPV. All subsequent demographics of the sample were measured at the initial assessment (Time 1). Participants of the current study ranged in age from 21 to 68 , with a mean age of 39.28 years $(S D=10.04)$. Cultural background of respondents was determined by their parents' birthplace. Out of them $44(59.5 \%)$ had Dutch parents, $8(10.8 \%)$ had a Western immigrant background ${ }^{3}$ and $22(29.7 \%)$ had a nonWestern background. ${ }^{4}$ Of all respondents, $68.9 \%$ was born in the Netherlands. A vast majority of the participants had one or more children (87.8\%). Somewhat more than half of the victims reported being divorced or separated from their abusive partner $(56.8 \%)$, and another $9.5 \%$ reported being married but wanting a divorce. About a quarter of

\footnotetext{
${ }^{3}$ Of these 8 respondents, 3 had a Portuguese background, 2 Indonesian, 1 Belgian, 1 Canadian, and 1 Bosnian background.

${ }^{4}$ Of these 22 respondents, 10 had a Surinamese background, 5 Moroccan, 4 Antillean/Aruban, 1 Turkish, 1 Burkinese, and 1 Cape Verdean background.
} 
participants $(24.3 \%)$ reported living under the same roof with the perpetrator of the violence. Only $4.1 \%$ lived in a shelter at the moment of our study. Most participants completed intermediate vocational education $(41.9 \%)$, a second group having completed lower vocational education (20.3\%). Only $44.6 \%$ held a paid job, the other $55.4 \%$ did not. The annual income of participants was rather low. Of the respondents that answered this question $(n=64), 75.0 \%$ had an income of less than 20,000 euro. Means, standard deviations $(S D)$, range of scores, and response scales on the independent and dependent variables included in our study can be found in Table 1. As Table 1 shows, the mean severity score was higher for psychological IPV revictimization than the severity score for physical IPV revictimization. On average, individuals in our sample were revictimized by their partners by a variety of approximately two acts of psychological violence and one act of physical violence. When we dichotomize our outcome measures, we see that $20(27.0 \%)$ victims have been revictimized by some form of physical IPV during the 2 month follow-up period, and $45(60.8 \%)$ victims have been revictimized by some form of psychological IPV. The mean follow-up period for our sample was approximately 2 months, namely 66.47 days $(S D=16.76$, range $53-177)$. There was some variety in the number of days, although almost no one exceeded a period of 3 months: $94.6 \%$ filled out the follow-up questionnaire within 90 days.

\section{Bivariate Correlations}

We examined Pearson correlations between our variables of interest. A correlation matrix showing bivariate correlations between independent and dependent variables in our study can be found in Table 2. It shows that all variables are significantly related to one or both of the revictimization outcome measures, except for anxious attachment style of the victim.

\section{Multivariate Analyses Insecure Attachment Styles}

To further explore the above findings that anxious attachment is not related to IPV revictimization and avoidant attachment is related to IPV revictimization, backward regression analyses were performed with both insecure attachment styles entered as independent variables. For severity of both physical as well as psychological IPV revictimization, it can be concluded that victims' anxious attachment style indeed is not a significant predictor (Table 3). On the other hand, it can be concluded that avoidant attachment is a strong predictor ( $\beta=.43, t=3.98, p \leq .001$ for severity of physical IPV revictimization and $\beta=.32, t=2.90, p=.005$ for severity of psychological IPV revictimization). Collinearity statistics (Tolerance $=0.97, \mathrm{VIF}=1.03$ ) indicate that there is no multicollinearity problem.

\section{Multivariate Tests of Interaction Models}

Within the avoidant attachment model, we hypothesized several interactions to predict revictimization of IPV, namely 1) avoidant attachment by anger in the victim, and 2) avoidant attachment by victim-perpetrated IPV. In subsequent analyses each predictor variable was converted into a deviation score as suggested by Aiken and West (1991) to reduce possible multicollinearity between predictors and to obtain more meaningful interpretations of the regression coefficients of the predictors. Predictors (victim-perpetrated IPV, avoidant attachment and anger) and interactions (avoidant attachment by anger and avoidant attachment by victim-perpetrated IPV) were entered in hierarchical regression analyses with severity of physical IPV revictimization and severity of psychological IPV revictimization as dependent variables respectively. Results showed that for severity of both physical as well as psychological IPV revictimization the interaction between avoidant attachment and the victim's own perpetration of IPV was not significant. Therefore, regression analyses were repeated without this interaction term, generating the final prediction model (Table 4). Main effects were shown for victim-perpetrated IPV $(\beta=.38, t=3.74, p \leq .001$ for physical and $\beta=.64, t=$ $7.30, p \leq .001$ for psychological IPV revictimization) and victims' avoidant attachment style $(\beta=.31, t=3.00, p=.004$ for physical and $\beta=.18, t=2.00, p=.050$ for psychological IPV revictimization). These variables thus predict the severity of revictimization of physical and psychological IPV respectively.
Table 1 Means, standard deviations (SD), range of scores and response scales of independent and dependent variables $(N=74)$

\begin{tabular}{lcccc}
\hline Variable & Mean & SD & Range of scores & Response scale \\
\hline Anxious attachment & 22.42 & 7.42 & $6-40$ & $6-42$ \\
Avoidant attachment & 22.23 & 7.51 & $9-38$ & $6-42$ \\
Anger & 14.42 & 5.74 & $7-28$ & $7-35$ \\
Victim-perpetrated IPV & 1.18 & 1.56 & $0-6$ & $0-7$ \\
Physical IPV revictimization & 1.18 & 2.63 & $0-11$ & $0-12$ \\
Psychological IPV revictimization & 2.21 & 2.24 & $0-7$ & $0-7$ \\
\hline
\end{tabular}


Table 2 Bivariate correlations for scores on attachment, anger, victim perpetration and revictimization measures

\begin{tabular}{|c|c|c|c|c|c|c|}
\hline Measure & 1 & 2 & 3 & 4 & 5 & 6 \\
\hline 1. Anxious attachment & - & & & & & \\
\hline 2. Avoidant attachment & -.17 & - & & & & \\
\hline 3. Anger & .14 & $.31 * *$ & - & & & \\
\hline 4. Victim-perpetrated IPV & -.10 & $.23 \dagger$ & $.20 \dagger$ & - & & \\
\hline 5. Physical IPV revictimization & -.05 & $.43 * * *$ & $.26^{*}$ & $.47 * * *$ & - & \\
\hline 6. Psychological IPV revictimization & .02 & $.32 * *$ & .18 & $.68 * * *$ & $.59 * * *$ & - \\
\hline
\end{tabular}

$\dagger p \leq .10, * p \leq .05, * * p \leq .01, * * * p \leq .001$

For anger in the victim, no significant main effect was found in both models. However, the interaction term of avoidant attachment by anger was significant for physical IPV $\left(\beta=.27,,^{5} t=2.68, p=.009\right)$; for psychological IPV a trend was shown $\left(\beta=.17,{ }^{6} t=1.83, p=.072\right)$. To investigate this interaction further, the regression lines between the victim's avoidant attachment and severity of IPV revictimization were plotted for high (i.e., one standard deviation above the mean), average (i.e., mean score) and low (i.e., one standard deviation below the mean) levels of anger in the victim (Fig. 1). From these plots and additional simple slope analyses it can be concluded that for victims with high and average anger levels, an avoidant attachment style is significantly and positively related to severity of both physical ( $p \leq .001$ for high and average anger) as well as psychological IPV revictimization ( $p \leq .001$ for high and $p=.008$ for average anger). However, for victims with low anger levels there is no significant relation between an avoidant attachment style and severity of physical and psychological IPV revictimization. ${ }^{7}$

\section{Discussion}

With the current study, we aimed to make a contribution to the development of theory on the role of victim-related psychological mechanisms in explaining risk for IPV revictimization. Within the two conflicting viewpoints on IPV - the gender perspective and the mutual IPV perspective - we identified two different sets of psychological victim variables that might explain risk

\footnotetext{
${ }^{5}$ This is the unstandardized solution from Friedrich's procedure (Friedrich 1982), which equals the appropriate standardized regression coefficient

${ }^{6}$ Idem

${ }^{7}$ Guidelines for plotting interactions do not permit the inclusion of more than three variables. Therefore, victim-perpetrated IPV was not included in Fig. 1a and b. Results from the simple slope analysis performed to test if the slopes of the regression lines are significantly different from zero do not include victim-perpetrated IPV either. However, when simple slope analyses are repeated including this variable, results are indicating the same pattern.
}

for IPV revictimization. From the gender perspective, we hypothesized that an anxious attachment style in the victim would prospectively predict IPV revictimization. Based on the mutual IPV perspective, we hypothesized an avoidant attachment style in the victim (and corresponding behaviors like rejecting the partner or pushing him away) to be a risk factor for IPV revictimization. In addition, we expected the risk for IPV revictimization to further increase if the avoidant attachment pattern in the victim occurred together with some aggression cues, such as feelings of anger or victim-perpetrated violence.

Results from our prospective study mainly support the hypotheses derived from the mutual IPV perspective. Bivariate as well as multivariate analyses showed that an anxious attachment style of the victim was not related to either physical or psychological IPV revictimization. In contrast, victims' avoidant attachment was a significant predictor for revictimization of both physical as well as psychological IPV. As an avoidant attachment style is characterized by rejecting and avoidant behavior from-in this case - the female partner, this finding supports the suggestion from the mutual IPV perspective that male violence in the domestic context can be viewed as an emotional reaction to frustration of the man's intimacy needs (Daly and Wilson 1988; Dutton 2008b; Dutton and Browning 1988). As such, the withdrawal from closeness and intimacy by avoidant victims is thought to lead to partner violence in a dysfunctional attempt (of the male partner) to keep the victim close (see Bartholomew et al. 2001). We also found a significant interaction between victims' avoidant attachment and anger. For victims with high and average anger levels, an avoidant attachment style was a significant predictor of both physical and psychological IPV revictimization, whereas for victims with low anger levels it was not. These results support the position put forward by Winkel (1999) that "frustration [...] in combination with some aggression cue is considered sufficient to elicit aggressive responses" (p. 275).

Our results suggest that avoidant behavior induces partner violence if it is accompanied by average or high anger levels in the victim. On the other hand, it seems that 
Table 3 Severity of (a) physical and (b) psychological IPV revictimization regressed on anxious and avoidant attachment $(N=74)$

\begin{tabular}{llllll}
\hline \multicolumn{7}{c}{ B } & SE B & $\beta$ & $\mathrm{t}$ \\
\hline I. Severity Physical IPV Revictimization & & & \\
Step 1 & Anxious Attachment & 0.01 & 0.04 & .03 & 0.25 \\
& Avoidant Attachment & 0.15 & 0.04 & .43 & $3.94 * * *$ \\
Step 2 & Avoidant Attachment & 0.15 & 0.04 & .43 & $3.98^{* * *}$ \\
II. Severity Psychological IPV Revictimization & & \\
Step 1 & Anxious Attachment & 0.03 & 0.03 & .08 & 0.67 \\
\multicolumn{7}{c}{ Avoidant Attachment } & 0.10 & 0.03 & .34 & $2.96^{* *}$ \\
Step 2 & Avoidant Attachment & 0.10 & 0.03 & .32 & $2.90^{* *}$ \\
\hline
\end{tabular}

Severity Physical IPV: Step 1: $R^{2}=18.1 \%$, Step $2: R^{2}=18.1 \%$. Severity Psychological IPV: Step 1: $R^{2}=11.0 \%$, Step 2: $R^{2}=10.5 \%$

${ }^{* *} p \leq .01, * * * p \leq .001$

victim anger as an aggression cue in itself is not strong enough to lead to IPV revictimization as victim anger did not show a main effect in predicting revictimization. This, however, is not to say that aggression cues from victims do not affect their risk of being revictimized by their partners' aggressive behavior. On the contrary: In further support of the mutual IPV perspective, we found a significant predictive effect for victim-perpetrated (psychological) violence. The expected interaction effect between avoidant attachment and victim-perpetrated IPV, however, was not significantly predictive of either physical or psychological IPV revictimization. The aggression cue of violence perpetrated by the victim thus appears strong enough to independently elicit IPV, regardless of whether the perpetrator is frustrated.
In summary, avoidant, angry and aggressive behavior on the part of the victim all, either directly or indirectly, influence the risk of IPV revictimization. In contrast, we did not find a predictive effect for victims' anxious attachment styles. As such, our results are supportive of the mutual IPV perspective, while we did not find support for the gender perspective on IPV. This latter finding is not in line with previous research that reports an anxious attachment style in the victim to be related to suffering IPV in both clinical (Bond and Bond 2004) as well as college samples (e.g., Bartholomew et al. 2001; Roberts and Noller 1998). However, these previous studies were cross-sectional in nature, whereas the current study is based on prospective data. Perhaps there is only a cross-sectional relation between anxious attachment and IPV victimization, yet no prospective one. Alternatively, anxious attachment might be related to victimization whereas it does not play a role in the mechanisms leading to revictimization. Our results supporting our mutual IPV hypotheses, on the other hand, are in line with previous research by Wekerle and Wolfe (1998), who reported an avoidant attachment style to be related to female IPV victimization. Our findings relating aggression cues, such as victim violence and anger to IPV revictimization, also build on prior research reporting correlations between these characteristics and IPV victimization (Anderson 2002; Burman et al. 1993; Capaldi et al. 2003; Cordova et al. 1993; Ehrensaft et al. 2004; Fergusson et al. 2005; Jacobson et al. 1994; Moffitt et al. 2001; Stith et al. 2004). The link between insecure attachment styles, anger, and intimate violence has furthermore been studied previously in a sample of IPV couples by Lafontaine and Lussier (2005). They also found an interaction effect

Table 4 Final regression models predicting severity of a) physical and b) psychological IPV revictimization $(N=74)$

\begin{tabular}{|c|c|c|c|c|c|}
\hline & & $\mathrm{B}$ & SE B & $\beta$ & $\mathrm{t}$ \\
\hline \multicolumn{6}{|c|}{ I. Severity Physical IPV Revictimization } \\
\hline \multirow[t]{3}{*}{ Step 1} & Victim-perpetrated IPV & 0.64 & 0.17 & .38 & $3.74 * * *$ \\
\hline & Avoidant Attachment & 0.11 & 0.04 & .31 & $3.00 * *$ \\
\hline & Anger & 0.04 & 0.05 & .09 & 0.86 \\
\hline \multirow[t]{2}{*}{ Step 2} & Interaction Avoidant & & & & \\
\hline & Attachment by Anger & 0.02 & 0.01 & $.27^{\mathrm{a}}$ & $2.68 * *$ \\
\hline \multicolumn{6}{|c|}{ II. Severity Psychological IPV Revictimization } \\
\hline \multirow[t]{3}{*}{ Step 1} & Victim-perpetrated IPV & 0.93 & 0.13 & .64 & $7.30^{* * *}$ \\
\hline & Avoidant Attachment & 0.05 & 0.03 & .18 & $2.00 *$ \\
\hline & Anger & -0.01 & 0.04 & -.01 & -0.09 \\
\hline \multirow[t]{2}{*}{ Step 2} & Interaction Avoidant & & & & \\
\hline & Attachment by Anger & 0.01 & 0.01 & $.17^{\mathrm{b}}$ & $1.83 \dagger$ \\
\hline
\end{tabular}

Severity Physical IPV: Step 1: $R^{2}=33.3 \%$, Step $2: \Delta R^{2}=6.3 \%, p \leq .01$. Severity Psychological IPV: Step 1: $R^{2}=49.5 \%$, Step $2: \Delta R^{2}=2.3 \%, p \leq .10$ $\dagger p \leq .10, * p \leq .05, * * p \leq .01, * * * p \leq .001$

${ }^{a}$ This is the unstandardized solution from Friedrich's procedure (Friedrich 1982), which equals the appropriate standardized regression coefficient ${ }^{\mathrm{b}}$ Idem 

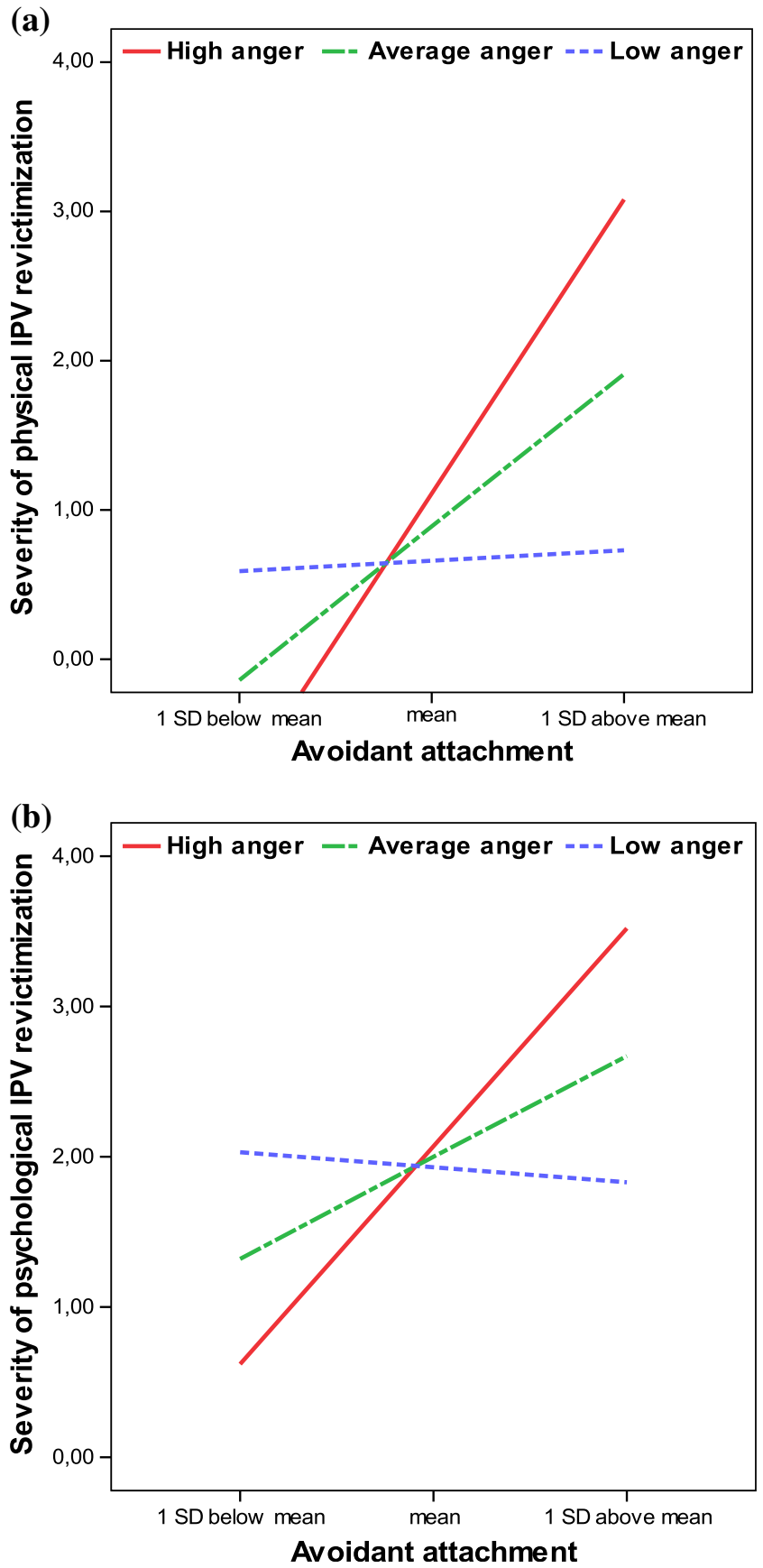

Fig. 1 Associations between avoidant attachment and severity of (a) physical and (b) psychological IPV revictimization for high, average and low anger levels in the victim

between insecure attachment and anger in predicting IPV. Yet, Lafontaine and Lussier used a cross-sectional design and did not differentiate between insecure attachment styles. Moreover, they only examined how anger and insecure attachment were related to IPV perpetration and not how it might have been related to risk for IPV (re) victimization.

To our knowledge, this is the first study to prospectively examine interactions between insecure attachment styles and victim anger and aggression among a sample of IPV victims and, thereby, it makes a relevant contribution to the literature. Our final model that integrates avoidant attachment and other aggression cues or - as Dutton (1995) labeled them - affective lability factors (i.e., victim anger and victim-perpetrated IPV) seems to indicate that emotional reactions of both partners play an important role in risk for IPV revictimization. Male IPV can be seen as an emotional reaction, for example to female avoidant behavior, female anger and female violence. Results of our prospective study suggest IPV to be an ongoing pattern of mutual violence perpetrated by both men and women, which has been supported by a large body of prior research as well (e.g., Archer 2000; Dutton 2008a; Stets and Straus 1989).

When interpreting the results of this study, however, several limitations need to be addressed. First, the sample size $(N=74)$ in the current study is rather small. In addition, our findings are based on a clinical sample of help-seeking victims of IPV. Therefore, results may not be generalizable to other victims of IPV that remain outside the scope of victim support organizations and do not seek help for their problems. However, it is not easy to reach this group of victims because some of them might not want to disclose the fact that they have been victimized by this particular form of violence due to fear for the perpetrator or feelings of shame and guilt. Furthermore, we only included IPV victims in our study. Although "the [...] victim is the best source of information about reabuse" (Bennett Cattaneo and Goodman 2005, p. 157), it would have been interesting to study IPV perpetrators as well, as we know that characteristics of both members of the couple influence risk (Moffitt et al. 2001).

Given the limitations to the current study, a number of areas in which further research is needed can be identified. Findings of the current study should be replicated in larger samples including non-clinical and non help-seeking victims in order to gain more support. It should be examined whether these victims share the same risk factors for revictimization as our victim sample, or whether other or additional relevant factors are present. On the other hand, it is also possible that non help-seeking victims are more resilient and able to cope with their problems themselves, and therefore are at lower risk for IPV revictimization. In addition, victims and perpetrators of partner violence should be included together in future studies to gain a more complete picture of the dyadic processes between them. For instance, in the current article we suggested that frustration in the male partner is created by the victim's avoidant behavior. Research including both partners could help in providing more empirical support for this suggestion. Furthermore, future research should focus on distinct anger features, like anger expression, anger control, state 
anger and trait anger. As previous research shows that the experience of anger differs within individuals with an insecure attachment style (Mikulincer 1998), it is important to study how these various anger components interact with insecure attachment patterns, such as anxious and avoidant behaviors, and how they relate to risk for revictimization. For example, it was found that in (anxious-)ambivalent individuals, their anger experience includes lack of anger control and a tendency to ruminate on anger feelings, whereas in avoidant individuals it is suggested to include high hostility, escapist responses and lack of awareness of physiological signs of anger (Mikulincer 1998). These findings further underline the relevance of distinguishing between these anger components in examining relations between anger, insecure attachment styles, and risk for revictimization of IPV.

In addition to recommendations for future research, the present study also provides us with several recommendations for practice. As the current and previous studies suggest that IPV is a dyadic process in which characteristics of both partners increase risk (Capaldi and Kim 2007; Moffitt et al. 2001), victim-related factors should be taken into account in conducting risk assessments. The final prediction model of the current study shows that victimperpetrated IPV is an important risk factor for physical and psychological IPV revictimization. An avoidant attachment style is a strong predictor as well, in particular for victims with high and average anger levels. We therefore recommend inclusion of these victim factors in existing risk assessment instruments (such as the ODARA, ${ }^{8}$ SARA $^{9}$ and B-SAFER ${ }^{10}$ ) that evaluate the risk for future (re)victimization of IPV. Assessment of additional victim-related factors will not only improve the prediction of risk for IPV, but will also provide opportunities to aim treatment and support activities at these victim characteristics in order to prevent future violence. Development of proper victim interventions is very important in the light of recent quantitative reviews that indicate that interventions for male batterers are not very effective in preventing reabuse (see Babcock et al. 2004; Feder and Wilson 2005). Simultaneous treatment of risk factors present in both partners within the couple thus seems a good strategy in the prevention of IPV revictimization. Furthermore, as avoidant and aggressive behaviors (i.e., affective lability) in victims have shown to increase their risk for IPV revictimization, it is important to support victims in achieving a more balanced affect and corresponding behavior. Interventions should be aimed at minimizing avoidant behavior, at reducing victims' anger

\footnotetext{
${ }^{8}$ Ontario Domestic Assault Risk Assessment; Hilton et al. 2004

${ }^{9}$ Spousal Assault Risk Assessment guide; Kropp et al. 1994, 1995

${ }^{10}$ Brief Spousal Assault Form for the Evaluation of Risk; Kropp et al. 2005
}

and use of violence, and at managing their feelings of aggression. Instead of using anger or violence as a way to cope with unpleasant experiences or threats, it may be advisable to focus on more effective coping styles as a strategy to decrease risk for revictimization, like problemfocused coping styles. In changing distressed romantic relationships, emotionally focused therapy (EFT; Johnson 1996) has shown to be a helpful strategy (Johnson et al. 1999). According to this approach, a partner's insecure attachment style may lead to defensive or avoidant responses to conflicts, such as unresponsiveness and inaccessibility, which in turn result in further conflict and dissatisfaction within the couple. This defensive behavior may also prevent relationship partners from providing support to and seeking support from one another during times of stress (see Edelstein and Shaver 2004, p. 407). The aim of EFT is to minimize these defensive and avoidant behaviors in response to conflict and to learn partners how they can use one another as source of support and comfort.

In conclusion, we can state that the relevance of the current study is apparent. It was the first study to prospectively and concurrently examine the two conflicting approaches to IPV the gender and mutual IPV perspective - by testing underlying psychological mechanisms derived from these approaches. Results lend further support to the mutual IPV perspective by showing an avoidant pattern in the victim to be significantly related to risk for IPV revictimization. Furthermore, findings showed the importance of the interaction between avoidant attachment and anger in IPV victims and moreover, victims' own violent behavior appeared to be an important risk factor for revictimization of IPV as well. Findings provide us with clear indications for risk assessment and treatment of IPV victims, and moreover offer opportunities to empower these victims in order to prevent future violence.

Acknowledgements This study is financially supported by the Achmea Foundation Victim and Society. Data collection was done in collaboration with Stichting Valkenhorst Breda, Bureau Slachtofferhulp Breda, Instituut voor Maatschappelijk Welzijn Breda, Veiligheidshuis Breda, Veiligheidshuis Bergen op Zoom, Traverse, GGZ Westelijk NoordBrabant, LEV-groep Helmond, Slachtofferloketten Openbaar Ministerie Breda, Middelburg, Utrecht, Den Haag and Rotterdam, and the "local domestic violence teams" with all their cooperating partners and organizations of GGD Rotterdam.

Open Access This article is distributed under the terms of the Creative Commons Attribution Noncommercial License which permits any noncommercial use, distribution, and reproduction in any medium, provided the original author(s) and source are credited.

\section{References}

Aiken, L. S., \& West, S. G. (1991). Multiple regression: Testing and interpreting interactions. Beverly Hills: Sage. 
Anderson, K. L. (2002). Perpetrator or victim? Relationships between intimate partner violence and well-being. Journal of Marriage and Family, 64, 851-863.

Archer, J. (2000). Sex differences in aggression between heterosexual partners: a meta-analytic review. Psychological Bulletin, 126, $651-680$

Babcock, J. C., Green, C. E., \& Robie, C. (2004). Does batterers' treatment work? A meta-analytic review of domestic violence treatment. Clinical Psychology Review, 23, 1023-1053.

Bartholomew, K., Henderson, A. J. Z., \& Dutton, D. G. (2001). Insecure attachment and abusive intimate relationships. In $\mathrm{C}$. Clulow (Ed.), Adult attachment and couple work: Applying the 'secure base' concept in research and practice (pp. 43-61). London: Routledge.

Bennett Cattaneo, L., \& Goodman, L. A. (2005). Risk factors for reabuse in intimate partner violence: a cross-disciplinary critical review. Trauma, Violence, and Abuse, 6, 141-175.

Bond, S. B., \& Bond, M. (2004). Attachment styles and violence within couples. Journal of Nervous and Mental Disease, 192, 857-863.

Burman, B., Margolin, G., \& John, R. S. (1993). America's angriest home videos: behavioral contingencies observed in home reenactments of marital conflict. Journal of Consulting and Clinical Psychology, 61, 28-39.

Capaldi, D. M., \& Kim, H. K. (2007). Typological approaches to violence in couples: a critique and alternative conceptual approach. Clinical Psychology Review, 27, 253-265.

Capaldi, D. M., Shortt, J. W., \& Crosby, L. (2003). Physical and psychological aggression in at-risk young couples: stability and change in young adulthood. Merrill-Palmer Quarterly, 49, $1-27$.

Classen, C. C., Palesh, O. G., \& Aggarwal, R. (2005). Sexual revictimization: a review of the empirical literature. Trauma, Violence, and Abuse, 6, 103-129.

Cordova, J. V., Jacobson, N. S., Gottman, J. M., Rushe, R., \& Cox, G. (1993). Negative reciprocity and communication in couples with a violent husband. Journal of Abnormal Psychology, 102, 559564.

Daly, M., \& Wilson, M. (1988). Homicide. New York: Aldine de Gruyter.

Dobash, R. E., \& Dobash, R. P. (1979). Violence against wives: A case against patriarchy. New York: Free.

Doumas, D. M., Pearson, C. L., Elgin, J. E., \& McKinley, L. L. (2008). Adult attachment as a risk factor for intimate partner violence. The "mispairing" of partners' attachment styles. Journal of Interpersonal Violence, 23, 616-634.

Dutton, D. G. (1995). A scale for measuring propensity for abusiveness. Journal of Family Violence, 10, 203-221.

Dutton, D. G. (2008a). My back pages: reflections on thirty years of domestic violence research. Trauma, Violence, and Abuse, 9, 131-143.

Dutton, D. G. (2008b). Caveat assessor: Potential pitfalls of generic assessment for intimate partner violence. In A. C. Baldry \& F. W. Winkel (Eds.), Intimate partner violence prevention and intervention: The risk assessment and management approach (pp. 125-131). New York: Nova Science Publishers, Inc.

Dutton, D. G., \& Browning, J. J. (1988). Concern for power, fear of intimacy, and aversive stimuli for wife assault. In G. Hotaling, D. Finkelhor, J. T. Kirkpatrick, \& M. A. Straus (Eds.), Family abuse and its consequences. New directions in research (pp. 130-175). Newbury Park: Sage.

Dutton, D. G., \& Starzomski, A. J. (1993). Borderline personality in perpetrators of psychological and physical abuse. Violence and Victims, 8, 327-337.

Edelstein, R. S., \& Shaver, P. R. (2004). Avoidant attachment: Exploration of an oxymoron. In D. J. Mashek \& A. Aron
(Eds.), Handbook of closeness and intimacy (pp. 397-412). Mahwah: Lawrence Erlbaum Associates, Inc.

Ehrensaft, M. K., Moffitt, T. E., \& Caspi, A. (2004). Clinically abusive relationships in an unselected birth cohort: men's and women's participation and developmental antecedents. Journal of Abnormal Psychology, 113, 258-271.

Farrell, G. (1992). Multiple victimisation: its extent and significance. International Review of Victimology, 2, 85-102.

Feder, L., \& Wilson, D. B. (2005). A meta-analytic review of court mandated batterer intervention programs: can courts affect abusers' behavior? Journal of Experimental Criminology, 1, 239-262.

Fergusson, D. M., Horwood, L. J., \& Ridder, E. M. (2005). Partner violence and mental health outcomes in a New Zealand birth cohort. Journal of Marriage and Family, 67, 1103-1119.

Follingstad, D. R., Rutledge, L. L., Berg, B. J., Hause, E. S., \& Polek, D. S. (1990). The role of emotional abuse in physically abusive relationships. Journal of Family Violence, 5, 107-120.

Forbes, D., Hawthorne, G., Elliott, P., McHugh, T., Biddle, D., Craemer, M., et al. (2004). A concise measure of anger in combat-related posttraumatic stress disorder. Journal of Traumatic Stress, 17, 249-256.

Friedrich, R. J. (1982). In defense of multiplicative terms in multiple regression equations. American Journal of Political Science, 26, 797-833.

Hawthorne, G., Mouthaan, J., Forbes, D., \& Novaco, R. W. (2006). Response categories and anger measurement: do fewer categories result in poorer measurement? Social Psychiatry and Psychiatric Epidemiology, 41, 164-172.

Hazan, C., \& Shaver, P. (1987). Romantic love conceptualized as an attachment process. Journal of Personality and Social Psychology, 52, 511-524.

Henderson, A. J. Z., Bartholomew, K., Trinke, S. J., \& Kwong, M. J. (2005). When loving means hurting: an exploration of attachment and intimate abuse in a community sample. Journal of Family Violence, 20, 219-230.

Hilton, N. Z., Harris, G. T., Rice, M. E., Lang, C., Cormier, C. A., \& Lines, K. J. (2004). A brief actuarial assessment for the prediction of wife assault recidivism: the Ontario domestic assault risk assessment. Psychological Assessment, $16,267-275$.

Jacobson, N. S., Gottman, J. M., Waltz, J., Rushe, R., Babcock, J., \& Holtzworth-Munroe, A. (1994). Affect, verbal content, and psychophysiology in the arguments of couples with a violent husband. Journal of Consulting and Clinical Psychology, 62, 982-988.

Johnson, S. M. (1996). The practice of emotionally-focused marital therapy: Creating connection. New York: Brunner/Mazel.

Johnson, S. M., Hunsley, J., Greenberg, L., \& Schindler, D. (1999). Emotionally focused couples therapy: status and challenges. Clinical Psychology: Science and Practice, 6, 67-79.

Kropp, P. R., Hart, S. D., Webster, C. D., \& Eaves, D. (1994). Manual for the spousal assault risk assessment guide. Vancouver: British Columbia Institute on Family Violence.

Kropp, P. R., Hart, S. D., Webster, C. D., \& Eaves, D. (1995). Manual for the spousal assault risk assessment guide (2nd ed.). Vancouver: British Columbia Institute on Family Violence.

Kropp, P. R., Hart, S. D., \& Belfrage, H. (2005). Brief Spousal Assault Form for the Evaluation of Risk (B-SAFER): User manual. Vancouver: ProActive ReSolutions Inc.

Lafontaine, M., \& Lussier, Y. (2005). Does anger towards the partner mediate and moderate the link between romantic attachment and intimate violence? Journal of Family Violence, 20, 349-361.

Miethe, T. D., Stafford, M. C., \& Scott Long, J. (1987). Social differentiation in criminal victimization: a test of routine 
activities/lifestyle theories. American Sociological Review, 52, 184-194.

Mikulincer, M. (1998). Adult attachment style and individual differences in functional versus dysfunctional experiences of anger. Journal of Personality and Social Psychology, 74, 513-524.

Moffitt, T. E., Caspi, A., Krueger, R. F., Magdol, L., Margolin, G., Silva, P. A., et al. (1997). Do partners agree about abuse in their relationship? A psychometric evaluation of interpartner agreement. Psychological Assessment, 9, 47-56.

Moffitt, T. E., Robins, R. W., \& Caspi, A. (2001). A couples analysis of partner abuse with implications for abuse-prevention policy. Criminology and Public Policy, 1, 5-37.

Murphy, K. R., \& Davidshofer, C. O. (1998). Psychological testing: Principles and applications (4th ed.). Upper Saddle River: Prentice-Hall.

Mustaine, E. E., \& Tewksbury, R. (1998). Predicting risks of larceny theft victimization: a routine activity analysis using refined lifestyle measures. Criminology, 36, 829-857.

Novaco, R. (1975). Dimensions of anger reactions. Irvine: University of California

Nunnally, J. C. (1978). Psychometric theory (2nd ed.). New York: McGraw-Hill.

Pitts, J., \& Smith, P. (1995). Preventing school bullying. Crime Detection and Prevention Series Paper no. 63. London: Home Office Police Department.

Roberts, N., \& Noller, P. (1998). The associations between adult attachment and couple violence: The role of communication patterns and relationship satisfaction. In J. A. Simpson \& W. S. Rholes (Eds.), Attachment theory and close relationships (pp. 317-350). New York: Guilford.

Sampson, R. J., \& Lauritsen, J. L. (1990). Deviant lifestyles, proximity to crime, and the offender-victim link in personal violence. Journal of Research in Crime and Delinquency, 27, 110-139.

Skogan, W. G. (1999). Victim surveys at century's end. In J. van Dijk, R. G. H. van Kaam, \& J. Wemmers (Eds.), Caring for crime victims: Selected proceedings of the 9th international symposium on victimology (pp. 41-53). Monsey: Criminal Justice.

Spielberger, C. D. (1988). Professional manual for the state-trait anger expression inventory (STAXI) (researchth ed.). Odessa: Psychological Assessment Resources.

Stets, J. E., \& Straus, M. A. (1989). The marriage license as a hitting license: a comparison of assaults in dating, cohabiting and married couples. Journal of Family Violence, 4, 161-180.
Stets, J. E., \& Straus, M. A. (1990). Gender differences in reporting marital violence and its medical and psychological consequences. In M. A. Straus \& R. Gelles (Eds.), Physical violence in American families: Risk factors and adaptations to violence in 8,145 families (pp. 151-165). New Brunswick: Transaction Books.

Stith, S. M., Smith, D. B., Penn, C. E., Ward, D. B., \& Tritt, D. (2004). Intimate partner physical abuse perpetration and victimization risk factors: a meta-analytic review. Aggression and Violent Behavior, 10, 65-98.

Straus, M. A. (2006). Cross-cultural reliability and validity of the multidimensional neglectful behavior scale Adult Recall Short Form. Child Abuse \& Neglect, 30, 1257-1279.

Straus, M. A., Gelles, R. J., \& Steinmetz, S. (1980). Behind closed doors: Violence in the American family. Garden City: Anchor/ Doubleday.

Straus, M. A., Hamby, S. L., Boney-McCoy, S., \& Sugarman, D. B. (1996). The revised Conflict Tactics Scale (CTS2): development and preliminary psychometric data. Journal of Family Issues, 17, 283-316.

Tilley, N. (1993). The prevention of crime against small businesses: The Safer Cities experience. Crime Prevention Unit Series Paper no. 45. London: Home Office.

Walby, S., \& Allen, J. (2004). Domestic violence, sexual assault and stalking: Findings from the British Crime Survey. Home Office Research Study 276. London: Home Office.

Walker, L. E. (1979). The battered woman. New York: Harper \& Row.

Walker, L. E. A. (1984). The battered woman syndrome. New York: Springer.

Walker, L. E. A. (2000). The battered woman syndrome (2nd ed.). New York: Springer.

Walker, L. E. A. (2009). The battered woman syndrome (3rd ed.). New York: Springer.

Wei, M., Russell, D. W., Mallinckrodt, B., \& Vogel, D. L. (2007). The experiences in close relationships scale (ECR)-short form: reliability, validity, and factor structure. Journal of Personality Assessment, 88, 187-204.

Wekerle, C., \& Wolfe, D. A. (1998). The role of child maltreatment and attachment style in adolescent relationship violence. Development and Psychopathology, 10, 571-586.

Winkel, F. W. (1999). A frustration/negative cue model of unfavorable police treatment of black citizens. Discrimination based on automatic and biased signal processing. International Journal of Law and Psychiatry, 22, 273-287. 